\title{
From the Origins of Pharmacogenetics to First Applications in Psychiatry
}

Authors

Daniel J. Müller¹, 2, 3, Zoe Rizhanovsky' ${ }^{1}$

\section{Affiliations}

1 Campbell Family Mental Health Research Institute, Centre for Addiction and Mental Health, Toronto, ON, Canada

2 Department of Psychiatry, University of Toronto, Toronto, ON, Canada

3 Department of Pharmacology, University of Toronto, Toronto, ON, Canada

\section{Key words}

pharmacogenetics, personalized medicine, psychopharmacology, antidepressants, antipsychotics

$\begin{array}{ll}\text { received } & 12.03 .2019 \\ \text { revised } & 07.06 .2019 \\ \text { accepted } & 11.07 .2019\end{array}$

\section{Bibliography}

DOI https://doi.org/10.1055/a-0979-2322

Published online: 23.9 .2019

Pharmacopsychiatry 2020; 53: 155-161

(C) Georg Thieme Verlag KG Stuttgart · New York

ISSN 0176-3679

\section{Correspondence}

Daniel J. Müller, MD PhD

Department of Psychiatry

University of Toronto Centre for Addiction and Mental

Health (CAMH)

250 College Street R132

M5T 1 R8 Toronto

Ontario

Canada

daniel.mueller@camh.ca

\begin{abstract}
Pharmacogenetics is the division of science addressing how genetic factors contribute to the metabolism, response, and side effects of a given medication. What was once regarded as a subdivision of genetics and pharmacology is now recognized as its own field and has its own unique story of origin. While the term "pharmacogenetics" was coined by Friedrich Vogel in 1959 , the relevance of inherited genetic traits in affecting the clinical outcome to xenobiotics has been observed long before. In fact, there is much hope that pharmacogenetics can help unravel the "mysteries" as to why different people may display variable responses to the same medication as well as identify new drug targets. This article will highlight the conceptual framework for pharmacogenetics advanced by pioneer scientists Arno Motulsky and Friedrich Vogel (both human geneticists), as well as Werner Kalow (clinical pharmacologist), leading up to the creation of modern pharmacogenetics. Finally, the practical implications and first steps toward implementation for current psychiatric treatment are reviewed followed by an outlook on future studies.
\end{abstract}

\section{Introduction to the History of Pharmacogenetics Pre-twentieth Century}

Pharmacogenetics is the branch of pharmacology and genetics concerned with the inter-individual metabolic and therapeutic responses to a given medication. Within pharmacogenetics there are two different but related fields. The first is pharmacodynamics, which

Dedicated to Peter Propping (1942-2016), Professor of Human Genetics. is concerned with the drug effects on the organism as a whole, and the second is pharmacokinetics, which studies the absorption, metabolism, and excretion pathways of the drug. Genetics and pharmacology have both considerably evolved from their respective rudimentary styles over the past few decades, and pharmacogenetics embraces both fields into a new branch with exciting research opportunities [1, 2].

As early as 1500 BC, the ancient Egyptians documented their understanding of medicine in the Papyrus of Ebers and showed an 
appreciation for "healing substances" albeit partly rooted in magic [3]. The ancient Greeks, too, advanced the scientific literacy, namely in genetics with their theory of "pangenesis." This early developmental theory of heredity was born out of the observation that both normal and pathological traits are passed on to offspring and must do so through an "information carrier" [4]. One could say, then, that the notions of clinical treatment and heredity were conceptually thought of as discrete constructs of science during the time of these ancient civilizations. This convention began to change, however, with the Greek scientist Pythagoras famously advising against the consumption of fava beans ("be far from the fava beans consumption"), noticing that it caused a condition (now known as acute hemolytic anemia) in certain people but not in others [5]. Despite the fact that Pythagoras did not remark a familial trend in his observations, at least in writing, the scientist did observe that the disease was more common in the Mediterranean area compared to other regions. While the concept of genetics was far from born, it is in retrospect that scientists still call this the first pharmacogenetics observation, as it perfectly demonstrates the melding of the fields of heredity and inter-individual outcomes to certain substances. In other words, Pythagoras observed that certain individuals could not tolerate an environmental agent that others could. The cause behind favism, elucidated at the turn of the twentieth century, was ascribed to a genetically inherited polymorphism of the gene that encodes for the enzyme glucose-6-phosphate dehydrogenase (G6PD) and can now easily be tested preemptively to avoid hemolytic anemia. With modern science's knowledge, it is natural to think of disease and genetics as inextricably linked, but this relationship has taken over a century of discoveries to fully develop. Pharmacogenetics research was limited following its unofficial inception in sixth century $B C$ until the development of classical Mendelian genetics in the mid-nineteenth century. A deeper understanding of allelic variation allowed certain inheritable diseases and pathologies to be reliably predicted-for example, Archibald Garrod's 1902 discovery of inherited alkaptonuria. This condition is caused by an autosomal recessive mutation in the detoxification enzyme homogentisate 1,2-dioxygenase leading to an inability to process two amino acids [6]. This discovery was important in that it laid the foundational groundwork for modern pharmacogenetics to build upon: the metabolism of molecular compounds can be altered by inherited genetic factors and cause an abnormal accumulation of "intermediate" metabolites. Garrod was therefore the first to explicitly link genetic variants with metabolites' variability, even though the molecular basis for these "inborn errors of metabolism" was only fully elucidated decades later [7]. "Traditional" pharmacogenetics progressed from looking at monogenic variation and drug response to looking at an entire host of genetic factors that interact with the environment [8]. Of particular importance was the discovery of the P450 cytochrome CYP2D6 gene, which encodes for a phase- 1 enzyme, responsible for the primary metabolism of at least 60 medications, and roughly $25 \%$ of clinically used medications [9]. Notably, the genetic architecture of CYP26 is highly variable among individuals and has more than 100 known allelic variants [9]. These variations are important because they help explain inter-individual differences in hydroxylation capacities and are an important consideration when administering psychiatric medications [10]. The discovery of the cytochrome family of genes permitted widespread population studies to be conducted and importantly helped to understand some of the interethnic differences to drug reactions [11]. Beginning as a mere concept in ancient Greece with Pythagoras to gaining a more firm ground in the scientific community thanks to $\mathrm{Ar}$ chibald Garrod showing a concrete connection between genetics and pharmacology, the field continues to flourish thanks to the contributions of a large scientific community. This article will highlight on the pioneering contributions made in the second half of the twentieth century by the scientists Arno Motulsky, Friedrich Vogel, and Werner Kalow, given that each of them played pivotal roles in laying the foundations for modern pharmacogenetics.

\section{Arno Motulsky (1923-2018)}

Professor Arno Motulsky, born in 1923 in Fischhausen (former Germany; now Primorsk, Russia), was a German-American physicianscientist who escaped Nazi Germany with his relatives at age 18 because of their Jewish heritage. He fled Germany aboard the SS St. Louis going to Cuba. The ship and its passengers, however, were denied entry and it was forced to return to France in 1939, where Motulsky spent a year in an internment camp. Ten days before his eighteenth birthday, the future scientist was able to leave France in 1941 and cross the border to Spain to board a ship to America. “Ten days and I wouldn't have made it," he reported later [12]. With a keen interest in medicine, he enrolled in premedical classes in a college in Chicago after his immigration to the United States. Soon after, he discovered his passion for biology and genetics at Yale University and eventually became a hematology instructor at the University of Washington [12]. Eager to set up a division of genetics, he became director of the first genetics institute in Seattle, Washington, in 1957. Importantly, he re-sparked the interest surrounding the field of medical genetics by instructing what he called "bootleg medical genetics" lectures, which combined his background in hematology and internal medicine with human genetics. Motulsky is regarded today as one of the fathers of modern genetics. Not only did he establish one of the first academic units to train medical genetics in the United States, but he also made impactful discoveries that greatly contributed to laying the conceptual groundwork for what would officially become the field of "pharmacogenetics." Motulsky earned his title of a father of pharmacogenetics because he led other scientists to bring the concept of genetics to the forefront when analyzing drug response variability. He writes in the 1957 JAMA publication, "It is not unlikely that some drug sensitivity reactions ... be produced by similar (genetic) mechanisms," which perfectly describes the inseparable link that genetics holds with drug response. ( $\vee$ Fig. 1)

What becomes evident when analyzing Motulsky's publications is that he emphasized the relationship between heredity and drug response long before mainstream medicine was doing so and, importantly, before modern genotyping was available to uncover the underlying biochemical mechanisms. While doing his fellowship in hematology, Motulsky had always been encouraged by his mentor Karl Singer to think about the possible biochemical mechanisms underlying diseases such as sickle cell anemia. Under this guidance, Motulsky had developed an appreciation for the "beautiful story" that genes and diseases tell and, importantly, was aware of the fact that better understanding their relationship would benefit patients 


\title{
DRUG REACTIONS, ENZYMES, AND BIOCHEMICAL GENETICS
}

\author{
Arno G. Motulsky, M.D., Seattle
}

In discussions of drug idiosyncrasy, careful distinction should be made between toxic reactions caused by immunologic mechanisms (drug allergy) and abnormal reaction caused by exaggeration or diminution of the usual effect of a given dose. ${ }^{1} \mathrm{Al}$ though some progress has been made in the study of mechanisms of drug allergy, little was known until recently about the pathogenesis of hypersusceptibility reactions and hyposusceptibility reactions. Data are available now which suggest that reactions of this type may be caused by otherwise innocuous genetic traits or enzyme deficiencies.

From the Department of School. Dr. Motulkky is a John and Mary R. Markle Scholar in Medical
Hockwald and his co-workers ${ }^{2}$ demonstrated that approximately $10 \%$ of American Negroes and a very small number of caucasians developed hemolytic anemia when given an average dose of primaquine or chemically related drugs. Beutler and associates : showed that red blood cells of susceptible individuals possessed decreased numbers of nonprotein, sulfhydryl groups. It has now been pointed out that primaquine sensitivity is related to glucose-6-phosphate dehydrogenase activity. ${ }^{4}$ Investigations of the genetics of this trait, now in progress, suggest that the abnormality is caused by a sex-linked gene of intermediate dominance. ${ }^{5}$ The red blood cell abnormality per se has no known deleterious effect on the individual or on red blood cell life span. Excessive doses

- Fig. 1 Arno Motulsky’s article “Drug Reactions, Enzymes and Biochemical Genetics” (1957) [14]. [rerif]

[13]. Two of his landmark findings are outlined in the 1957 JAMA paper titled "Drug Reactions, Enzymes, and Biochemical Genetics."

The first describes the observation made during the Korean War (1950-1953), when he was working at the Army Medical Center in Washington D.C. and studying blood disorders [14]. In parallel to Pythagoras's observations of favism intolerance, Motulsky noticed that some men given an average dose of primaquine (an antimalarial drug) would develop hemolytic anemia while most men would tolerate this medication very well. Although Motulsky suspected a genetic polymorphism to be behind the cause of the two drug-response phenotypes, the exact mechanism was not explained until 1955 when Beutler et al. showed that hemolytic anemia was in fact caused by a deficiency in the enzyme G6PD [15]. It was later found out that approximately $10 \%$ of African-American soldiers were G6PD deficient. This is a prime example of how a genetic polymorphism alone may not have severe consequences on an individual's life but, when exposed to a certain drug, can produce significant adverse events. Another important discovery relates to a genetic polymorphism discovered in the gene that encodes for the enzyme pseudocholinesterase. Following administration of the drug succinylcholine (a muscle relaxant), most individuals rapidly destroyed the drug, and its use was benign. Motulsky noticed, however, that in some individuals, the drug was not metabolized normally, and they developed prolonged apnea that required artificial respiration. Upon further investigation Motulsky discovered this side effect was not due to the disease but rather due to a heritable change in the enzyme itself [16].

\section{Friedrich Vogel (1925-2006)}

A second important contributor to the field of pharmacogenetics was Professor Friedrich Vogel, who was born in Berlin (Germany) in 1925. At age 19, he was conscripted to the army but soon after became a prisoner of war to the Soviet Union. After almost dying from ill health and starvation, he was released in autumn of 1945 and was able to return to Germany, where he pursued his career in science [17]. After earning his medical degree at age 28 in 1953, Vogel entered the field of human genetics to take the "road less travelled," a testimony to how newly budding the field was at the time [18]. Particularly, the geneticist wished to advance what was known on monogenetically controlled adverse drug reactions. Vogel took an interest in hepatic porphyria, which is caused by a deficiency of the enzyme ALA synthetase. Albeit a relatively rare disease in humans, it was known to be an autosomal dominant disease. Also, certain drugs (barbiturates, sulfonal, and glutethimide) seemed to worsen the symptoms of porphyria in individuals with the defective copy of ALA synthetase but had no negative toxic side effects on other individuals [19]. Studies conducted by Harris et al. on the variability of taste perception of phenylthiourea and its association with thyroid-related disorders also showed a gene-antithyroid drug relationship [20]. These cases in particular are what inspired Vogel to officially coin the term "pharmacogenetics" in 1959, as the close contact between genetics and pharmacology was beginning to become increasingly evident [21] ( $\triangleright$ Fig. 2).

Vogel and Motulsky were two colleagues who developed a friendship that led to them publishing the first edition of their leading textbook in 1979: Human Genetics: Problems and Approaches, now on its fourth edition and translated into other languages such as Italian, Japanese, Chinese, and Russian. They present their past experimental observations to the younger generations in a practical way that encourages young scientists to critically think about how to solve genetics-related cases rather than to just "add another brick to the edifice," which further highlights the importance of mentoring to the two scientists [13]. Given his international reputation, in 1986, he was invited to organize the seventh International Congress of Human Genetics in Berlin [17]. Notably, following the mass-murdering of individuals with mental illnesses during World War II-based on ill-defined eugenic concepts-genetic research, and in particular psychiatric genetic research, has remained particularly challenging and has since been met with higher skepticism [22]. Perhaps a lesser-known facet of Vogel's legacy is his contribution to debunking the concept of eugenics, a term coined by Francis Galton in 1883. It was while studying retinoblastoma in newborns that Vogel reached the conclusion that eugenics had no rational basis, thus dissipating the "degeneration concepts" postulated since the nineteenth century, which led to the deportation and euthanasia of thousands of individuals (including the mentally ill) during the years of World War II [17]. 


\title{
II. Moderne Probleme der Humangenetik
}

\author{
Von
}

Friedrich VogeL*

\section{Ansätze zu einer Pharmakogenetik des Menschen}

Der Ausdruck „Pharmakogenetik“ des Menschen, den wir zur Überschrift dieses Kapitels wählten, ist bisher noch mehr ein Programm als eine Bezeichnung für ein Arbeitsgebiet. Bisher sind zu einer Kenntnis der erblichen Varianten in der Reaktion auf Arzneimittel und sonstige von außen zugeführte Stoffe nur Ansätze vorhanden. Zum größten Teil liegt das sicher daran, daß diese Beziehungen einfach noch kaum untersucht sind; einzelne Beobachtungen scheinen darauf hinzudeuten, daß das ganze Gebiet in Zukunft immer wichtiger werden dürfte.

Fig. 2 Friedrich Vogel's article “II. Moderne Probleme der Humangenetik," which coined the term "pharmacogenetics” (1959) [21]. [rerif]

\section{Werner Kalow (1917-2008)}

The third important character that solidified pharmacogenetics as a legitimate scientific field in the postwar era was the German-Canadian Professor Werner Kalow, born in Cottbus (Germany) in 1917. Kalow began his career as a physician for the German Navy in 1938. He was drafted to serve on a blockade runner, surviving many attacks before the ship was scuttled just before the U.S. Navy could capture the vessel in January 1944. The crew was rescued in their life boats and Kalow was taken to Arizona as prisoner of war. Luckily for Kalow, the American Army was in need of hospital staff and recruited him to assist in patient care in 1944. Upon his return to Germany in 1946, he entered the field of clinical work and took up the fundamentals of pharmacology, beginning with studying the "fate" of medications after being taken up by the body [23]. In Germany, Kalow's work on enzyme absorption and activity caught the attention of visiting American scientists in 1949, and he was recruited to the United States to further his studies using more specialized equipment than was available in postwar Germany [23]. Kalow was invited to the Department of Pharmacology in Philadelphia, where he met Ken Ferguson, then the Director of Pharmacology at the University of Toronto. Eventually, in 1951, Kalow was offered a position at the University of Toronto, where he took up a faculty position, partly because of his appreciation for what he called the "Canadian peaceful serenity" [24]. As a resident Toronto pharmacologist, one of Kalow's important contributions to the budding field was in 1956 when he discovered the genetic variants of plasma cholinesterase (referred as either "atypical" or "usual" variants). Using novel spectrophotometric techniques, Kalow analyzed how these variants metabolized the drug succinylcholine differently [25]. With this finding, and encouraged by Motulsky's article "Drug Reactions, Enzymes, and Biochemical Genetics” (1957), which included Kalow's experiments done on pseudocholinesterase, Kalow was inspired to publish the landmark monograph Pharmacogenetics: Heredity and the Response to Drugs (1962). This 222-page book is the first work entirely dedicated to the field, coherently summarizes all the work and available knowledge of that time, and is recognized as heightening the profile of pharmacogenetics from a subspecialty to an entire field (॰ Fig. 3).

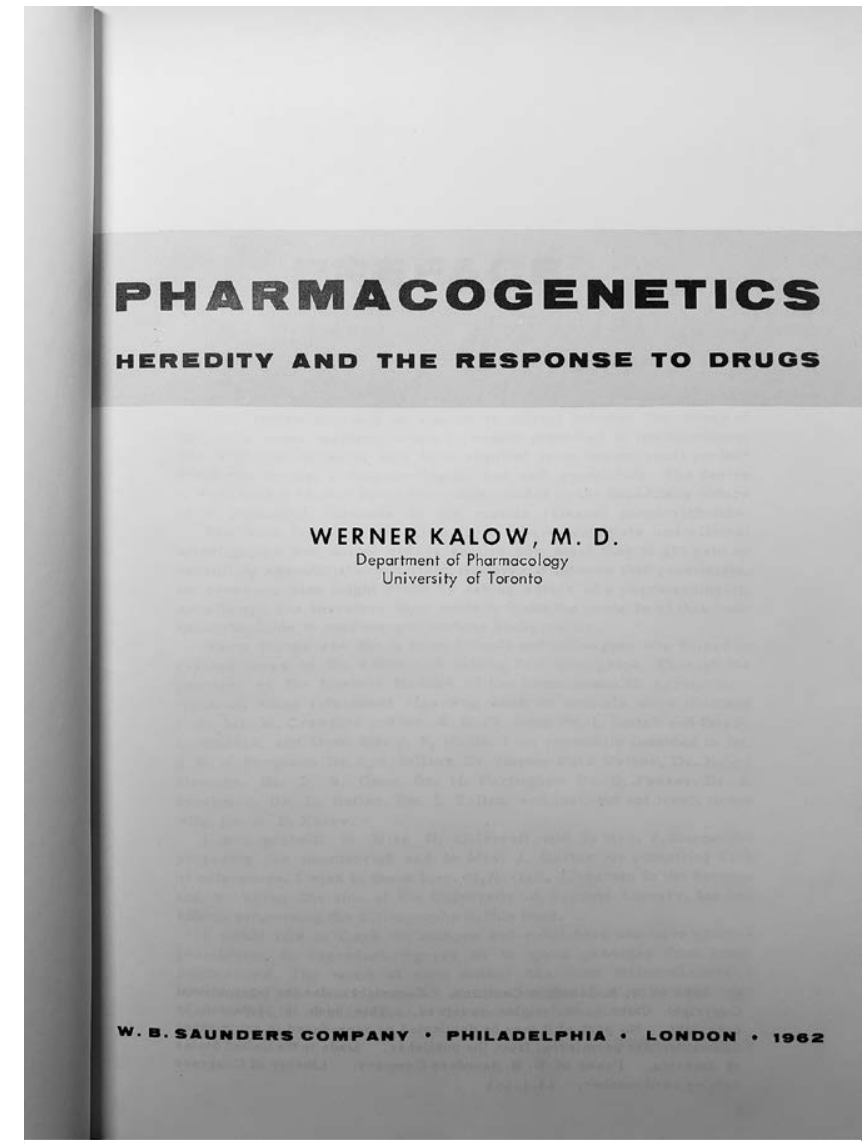

- Fig. 3 Werner Kalow's book Pharmacogenetics: Heredity and the Response to Drugs (1962). [rerif]

While studying different genetic variants and their corresponding enzymatic functions, Kalow noticed the markedly different drug responses to the poison phenylethanolamine in different animals and also detected different enzyme-substrate affinities between humans and horses [23]. It was therefore evident that interspecies variation was behind the measurable discrepancies in enzyme activity, and he hypothesized that there would be variation on a smaller scale 
as well, within the same species. He incorporated an evolutionary basis for the discrepancies into his logic, stating that different enzymes evolved to manage different environmental toxins and thus react to drugs uniquely. Kalow therefore judged that heritable pharmacogenetics differences would be seen between the ethnic races, as the different groups evolved in different geographical locations, which he could prove through his studies. He noted that in one of his studies on the metabolism of amobarbital, seven out of 140 students did not produce the normal metabolite, and on further investigation, the seven students were all of Chinese origin [26]. Kalow was thus the first researcher to formally publish an article discussing the interethnic differences in drug metabolism in 1982 [27]. In addition to highlighting the genetic variation between ethnic groups, Kalow also advanced the field of pharmacogenetics by underlining the fact that most pharmacological differences are indeed polygenic and interacting with environmental factors [28]. The discovery of the hepatic cytochrome P450 family of enzymes now allows scientists to screen patients' genes to determine the cause of a negative reaction, and there is even the possibility of screening these genes to anticipate a negative response to a drug [29].

\section{Post-WWII advancements}

In summary, it is remarkable to recognize that despite undergoing the hardships surrounding the events and horrors of World War IIall attributed their survival to "pure luck"-the three scientists overcame their personal adverse experiences and became pioneers in establishing genetics as an important scientific field. Notably, following the atrocities conducted on the misguided ideologies of the eugenics movement, establishing confidence in genetic research, and in particular psychiatric genetic research, presented a challenge for the scientists. Likely because Motulsky, Vogel, and Kalow suffered personal consequences by the ill-informed pseudoscience of "eugenics," they developed a particular interest in debunking the unfounded, scientifically wrong concepts put forth by the eugenics movement while shedding light on the opportunities in the new emerging field of genetics and pharmacogenetics.

While the conceptual framework of pharmacogenetics was first recognized and discussed in the first 15 years following World War II, the technological resources remained limited. It was mostly thanks to the development of the polymerase chain reaction technique in 1985, fluorescent in situ hybridization in 1980, and northern and southern blotting in the 1990s that novel molecular genetic techniques became readily available to study deletions, duplications, and translocations in DNA [30]. In this context, it is not surprising that the second edition of the textbook Human Genetics, edited by Vogel and Motulsky and published in 1986, only dedicated 7 out of 700 pages to illustrate the field and discoveries made in pharmacogenetics. This era of 'hibernation' came to a rapid halt as new molecular genetic research laboratories became widely available in the 1990s, and the field has since witnessed an exponential increase of genetic and interest in pharmacogenetics. For example, a PubMed search for "Pharmacogenetics" between the years of 1980 and 1990 yields 184 results over the decade. In contrast, the same search done between the years of 2010 and 2019 yields 9417 results (and counting). This translates to approximately 1000 studies a year being published on a topic relevant to the field of pharmacogenetics.

\section{Clinical implications for psychiatry}

Given the large number of studies conducted since, expert groups have emerged to evaluate the clinical relevance of specific gene-drug pairs with highest level of clinical evidence [31]. Those groups, such as the Dutch Pharmacogenomics Working Group or the Clinical Pharmacogenetics Implementation Consortium (CPIC), seek to provide evidence-based recommendations for specific gene-drug pairs [32]. As of early 2019, CPIC has provided expert recommendations for a large group of psychiatric medications-that is, tricyclic antidepressants (CYP2D6 and CYP2C19 genes), selective serotonin reuptake inhibitors (SSRIs) (CYP2D6 and CYP2C19 genes), atomoxetine (for CYP2D6 gene), and carbamazepine (HLA-A and HLA-B genes) [33-36]. Other gene-drug pairs such as ABCB1 gene variants and antidepressants (e. g., Breitenstein et al., 2016) or gene variants involved in exposure to antipsychotics (e. g., Yoshida and Müller) have not yet been evaluated for CPIC guidelines [37, 38]. Notably, the Pharmacogene Variation Consortium was recently inaugurated as a "central online repository for pharmacogene (PGx) variation that focuses on haplotype structure and allelic variation, which facilitates access to relevant pharmacogenetic information and supports the evolution for new nomenclatures" [39]. Such efforts remain important to identify presence of new allelic variants in and differences across different ethnic groups as these will help to personalize and optimize medication treatment globally. For example, the Food and Drug Administration recommends screening for the HLA-A * 3101 and HLA-B * 1502 allele prior to carbamazepine treatment due to a high risk of serious and potentially lethal dermatologic reactions bit do so only for patients of East Asian descent, as these specific alleles have rarely been observed in other populations. However, ethnicity-based recommendations, particularly if purely based on appearances, remain challenging for mixed population groups due to possible de novo genetic variations.

Of note, most expert recommendations (e. g., for CYP2D6 or CYP2C19 for TCA or SSRI antidepressants) are based on retrospective evaluations of published studies while cost-effectiveness studies supporting the widespread us of pharmacogenetic tests remain to be addressed. As for the few prospective studies evaluating pharmacogenetic testing in psychiatry, a recent meta-analysis on five independent studies (using commercial test kits) comparing pharmacogenetic-based treatment (PBT) versus treatment as usual (TAU) have shown that PBT was 1.7 times more likely to achieve response and remission to treatment compared to TAU [40]. Given that the costs for genotyping have steadily dropped, access and affordability of genetic testing has steadily increased. Supported by feasibility studies noting high acceptance and demand by physicians and patient, with no harmful effects noted for patients, such testing is likely to expand further in clinical practice [41]. With respect to the allelic variants to be selected in a test panel, a recent review of the literature suggests that six genes would meet evidence-based criteria to optimize psychiatric treatment for several antidepressants (CYP2D6 and CYP2C19) and for two antiepileptics/mood stabilizers (CYP2C9, HLA-A, and HLA-B) [42]. Notably, the majority of current recommendations are related to pharmacokinetic gene drug pairs, which raises the question of how pharmacogenetics differentiates itself from therapeutic drug monitoring (TDM) [43]. While a detailed comparison between TDM and pharmacogenetics is beyond the scope of this article, both should be regarded as complimen- 
tary strategies with their own contributions to treatment optimization. Perhaps the main distinctions are that TDM only allows for any type of measurement after medication was taken, while pharmacogenetic assessments can be done preemptively (i. e., before medication is taken). Implementation of pharmacogenetic testing is spreading in medical centers that have started to routinely provide pharmacogenetic testing for psychiatric patients [44, 45]. Also, despite their lack of standardization by regulatory agencies and lack of gene-specific recommendations, commercial tests have become available to the public, including tests that are restricted to be ordered by physicians $[46,47]$.

\section{Outlook: toward a new era of precision medicine}

Besides classic genetic analyses exploring DNA sequence variation, complementary efforts are being made to studying gene transcripts, giving rise to the field of transcriptomics to study more specifically the complete set of RNA molecules that may interact with a given medication [48]. Additionally, epigenetic considerations are also taken into account when studying drug-gene interactions. An example might be the 2018 study by Palma-Gudiel et al. analyzing DNA methylation of the serotonin transporter SLC6A4 gene. Their findings show that hypermethylation is correlated with higher scores on the Brief Symptom Inventory evaluation, which tests for depressive-anxious symptoms [49]. Likewise, one study analyzed the methylation sites on the serotonin transporter gene 5-HTT, suggesting that hypomethylation is associated with decreased serotonin availability and, consequently, less-effective treatment responses [50]. If further validated, such epigenetic markers might be used to further enhance and improve pharmacogenetic test panels. Additionally, scientists have now begun using computer science tools (i. e., machine learning models) in genomic ("big") data with first promising studies for psychiatric pharmacogenetics emerging. For example, one pilot study used machine learning methods to analyze duloxetine treatment response for patients with major depressive disorder, showing the feasibility of combining machine learning techniques with genomic data sets [51].

\section{Conclusions}

Pharmacogenetic concepts have contributed enormously to spark the revolution of "personalized medicine," which aims to greatly increase the likelihood for optimal response and reduce the incidence of therapeutic failures and adverse reactions. This field continues to grow and gain importance in an exponential fashion, thanks also to the insightful work performed by pioneering scientists such as Arno Motulsky, Freidrich Vogel, and Werner Kalow following the first decades after World War II. From analyzing simple single-gene variations at very high costs a few decades ago to analyzing thousands of allelic variants at relatively low costs today, laboratories will soon offer sequencing entire genome for less than $\$ 1000$ per individual. With the first set of genes recommended for testing prior to medication intake, genomic medicine is becoming a reality in psychiatry.

\section{Conflict of Interest}

Authors declare that they have no conflict of interest.
References

[1] Meyer UA. Pharmacogenetics - five decades of therapeutic lessons from genetic diversity. Nat Rev Genet 2004; 5: 669-676

[2] Charlab R, Zhang L. Pharmacogenomics: Historical perspective and current status. Methods Mol Biol 2013; 15: 3-22

[3] Sipos P, Gyõry H, Hagymási K et al. Special wound healing methods used in ancient Egypt and the mythological background. World J Surg 2004; 28: 211-216

[4] Vogel F, Motulsky A. Human Genetics: Problems and Approaches. New York: Springer-Verlag; 1979

[5] Meletis J. Favism: a brief history from the "abstain from beans" of Pythagoras to the present. Arch Hellenic Med 2012; 29: 258-263

[6] Prasad C, Galbraith PA. Sir Archibald Garrod and Alkaptonuria - 'story of metabolic genetics'. Clin Genet 2005; 68: 199-203

[7] Roden DM, Wilke RA, Kroemer HK et al. Pharmacogenetics: The genetics of variable drug responses. Circulation 2011; 123: 1661-1670

[8] Kalow W. Pharmacogenetics and personalised medicine. Fundam Clin Pharmacol 2002; 16: 337-342

[9] Fang H, Liu X, Ramirez J et al. Establishment of CYP2D6 reference samples by multiple validated genotyping platforms. Pharmacogenomic J 2014; 14: 564-572

[10] Brown et al. Clinical Utilization of Pharmacogenetics in Psychiatry Perspectives of Pharmacists, Genetic Counselors, Implementation Science, Clinicians, and Industry. Pharmacopsychiatry 2019, DOI: https://doi.org/10.1055/a-0975-9595

[11] Innocenti F. Pharmacogenetics: Methods and Protocols. Totowa: Humana Press; 2005

[12] Motulsky A. Holding out hope in a cruel world: geneticist Arno Motulsky recalls wartime Europe. UW. Medicine 2002; 25: 9-12

[13] King M. The great adventure of an American human geneticist. Annu Rev Hum Genet 2016; 17: 1-15

[14] Motulsky A. Drug reactions, enzymes and biochemical genetics. JAMA 1957; 165: 835-837

[15] Beutler $E$. The hemolytic effect of primaquine and related compounds: A review. J Hematol 1959; 14: 103-139

[16] Motulsky A. Metabolic polymorphisms and the role of infectious diseases in human evolution. Hum Biol 1960; 32: 28-62

[17] Propping P, Bartram CR. Friedrich Vogel 1923-2006. Hum Genet 2007; 120: $751-753$

[18] Sperling K. Obituary: Prof. Dr. med. Dr. h. c. Friedrich Vogel (19252006). Hum Genet 2007; 120: 755-757

[19] Vogel H]. Metabolic Regulation: Metabolic Pathways. New York: Academic Press; 1971

[20] Scott SA. Personalizing medicine with clinical pharmacogenetics. Genet Med 2011; 13: 987-995

[21] Vogel F. Moderne problem der humangenetik. Ergeb Inn Med U Kinderheilk 1959;12: 52125

[22] Schulze TG, Fangerau H, Propping P. From degeneration to genetic susceptibility, from eugenics to genethics, from Bezugsziffer to LOD score: the history of psychiatric genetics. Int Rev Psychiatry 2004; 16: 246-259

[23] Jones DS. How personalized medicine became genetic, and racial: Werner Kalow and the formations of pharmacogenetics. J Hist Med Allied Sci 2013; 68: 1-48

[24] Kalow W. A Colorful Life: Youth in Hitler Germany, Seafaring in Worldwar-2, Studies of Drugs and Genes, University of Toronto. 2006

[25] Kalow W. Familial incidence of low pseudocholinesterase level. Lancet 1956; 268: 576-577

[26] Kalow W, Tang BK, Kadar D et al. A method to study drug metabolism in populations: Racial differences in amobarbital metabolism. Clin Pharmacol Ther 1979; 26: 766-776 
[27] Kalow W. Ethnic differences in drug metabolism. Clin Pharmacokinet 1982; 7: 373-400

[28] Kalow W. Human pharmacogenetics: the development of a science. Hum Genomics 2004; 1: 375-380

[29] Kalow W. Pharmacogenetics: historical perspectives and current status. Methods Mol Biol 2005; 311: 3-15

[30] Durmaz AA, Karaca E, Demkow U et al. Evolution of genetic techniques: Past, present, and beyond. Biomed Res Int 2015; 15: 1-7

[31] Bousman CA, Zierhut H, Müller DJ. Navigating the labyrinth of pharmacogenetic testing: A guide to test selection. Clin Pharmacol Ther 2019 Apr 20 [Epub ahead of print]

[32] Caudle KE, Klein TE, Hoffman JM et al. Incorporation of pharmacogenomics into routine clinical practice: the Clinical Pharmacogenetics Implementation Consortium (CPIC) guideline development process. Curr Drug Metab 2014; 15: 209-217

[33] Hicks JK, Bishop J, Sangkuhl K et al. Clinical Pharmacogenetics Implementation Consortium (CPIC) guideline for CYP2D6 and CYP2C19 genotypes and dosing of selective serotonin reuptake inhibitors. Clin Pharmacol Ther 2015; 98: 127-134

[34] Hicks JK, Sangkuhl K, Swen JJ et al. Clinical Pharmacogenetics Implementation Consortium guideline (CPIC $\left.{ }^{\circledR}\right)$ for CYP2D6 and CYP2C19 genotypes and dosing of tricyclic antidepressants: 2016 Update. Clin Pharmacol Ther 2017; 102: 37-44

[35] Brown JT, Bishop JR, Sangkuhl K et al. Clinical Pharmacogenetics Implementation Consortium (CPIC) guideline for CYP2D6 genotype and atomoxetine therapy. Clin Pharmacol Ther 2019; 106: 94-102

[36] Phillips E], Sukasem C, Whirl-Carrillo M et al. Clinical Pharmacogenetics Implementation Consortium guideline for HLA genotype and use of carbamazepine and oxcarbazepine: 2017 update. Clin Pharmacol Ther 2018; 103: 574-581

[37] Breitenstein B, Scheuer S, Brückl TM et al. Association of ABCB1 gene variants, plasma antidepressant concentration, and treatment response: results from a randomized clinical study. J Psychiatr Res 2016; 73: 86-95

[38] Yoshida K, Muller DJ, Kennedy JL. The coming-of-age of pharmacogenetic testing in clinical psychiatry. Psychiatry Clin Neurosci 2019; 73: 203

[39] Gaedigk A, Dinh JC, Jeong $\mathrm{H}$ et al. Ten years' experience with the CYP2D6 activity score: A perspective on future investigations to improve clinical predictions for precision therapeutics. J Pers Med 2018; 8: 15
[40] Bousman CA, Arandjelovic K, Mancuso SG et al. Pharmacogenetic tests and depressive symptom remission: A meta-analysis of randomized controlled trials. Pharmacogenomics 2019; 20: 37-47

[41] Walden LM, Brandl EJ, Tiwari AK et al. Genetic testing for CYP2D6 and CYP2C19 suggests improved outcome for antidepressant and antipsychotic medication. Psychiatry Res 2018 Mar 9 [Epub ahead of print]

[42] Bousman C, Maruf AA, Müller DJ. Towards the integration of pharmacogenetics in psychiatry: A minimum, evidence-based genetic testing panel. Curr Opin Psychiatry 2019; 32: 7

[43] Hiemke C, Bergemann N, Clement HW et al. Consensus guidelines for therapeutic drug monitoring in neuropsychopharmacology: Update 2017. Pharmacopsychiatry 2018; 51: e1

[44] Müller D], Kekin I, Amy CC et al. Towards the implementation of CYP2D6 and CYP2C19 genotypes in clinical practice: Update and report from a pharmacogenetic service clinic. Int Rev Psychiatry 2013; 25: 554-571

[45] Mrazek DA. Psychiatric pharmacogenomic testing in clinical practice. Dialogues Clin Neurosci 2010; 12: 69-76

[46] Hopwood M, Bousman CA. Commercial pharmacogenetic-based decision-support tools in psychiatry. Lancet Psychiatry 2016; 3: 585-590

[47] Fan M, Bousman CA. Commercial pharmacogenetic tests in psychiatry: Do they facilitate the implementation of pharmacogenetic dosing guidelines? Pharmacopsychiatry 2019; 52: 1-5

[48] Ludvigsen M, Honoré B. Transcriptomics and Proteomics: Integration? In eLS. John Wiley \& Sons, Ltd; Ed. 2018

[49] Palma-Gudiel H, Peralta B, Deuschle M et al. Epigenetics-by-sex interaction for somatization conferred by methylation at the promoter region of SLC6A4 gene. Prog Neuropsychopharmacol Biol Psychiatry 2018; 89: 125-131

[50] Domschke K, Tidow N, Schwarte K et al. Serotonin transporter gene hypomethylation predicts impaired antidepressant treatment response. Int J Neuropsychopharmacol 2014; 17: 1167-1176

[51] Maciukiewicz M, Marshe VS, Hauschild AC et al. GWAS-based machine learning approach to predict duloxetine response in major depressive disorder. J Psychiatr Res 2018; 99: 62-68 